\section{Working for trainees}

\section{The Collegiate Trainees' Committee}

Have you considered the following questions?

Who are your local Collegiate Trainees' Committee (CTC) representatives?

What are the issues they need to know about?

How will College decisions affect me in the short term and in the long term?

Who will replace my current representatives?

Do you know when elections are held and how to stand?

Do you wish to travel, meet trainees and improve your CV?

Can you do a better job than your current representatives?

In 1989 the CTC celebrated its tenth anniversary. Although it is a special committee of the Royal College of Psychiatrists little is known of its existence. The CTC is directly responsible to the Council and now has at least one trainee on every committee of the College except the Court of Electors. The functions of the CTC have been described in the Bulletin (Scott, 1986). This article describes the present composition of the CTC and defines its present activities. The committee consists of 36 elected trainees. The Dean is an exofficio member and attends all our meetings. Each division of the College in England and Wales is represented by three trainees (of whom at least one is an inceptor) while Scotland and Ireland (North and South) are represented by six trainees each. The CTC meets at the time of the College quarterly meetings with an additional residential weekend meeting each September.

Information is available on 36 of the 37 current members. There are 23 males and the present committee is predominantly young in terms of age and time since graduation.

There are two senior house officers, 14 registrars, 16 senior registrars and three lecturers; 26 are members of the College and five are in addition members of other Colleges. There are only two part-time doctors, 25 are based in teaching hospitals, 20 were elected unopposed, 13 contested elections and three were co-opted on to the committee.

The most common reason for joining the CTC was to obtain information about activities related to psychiatry and or training. Over half indicated gaining experience of committee meetings and influencing decision-making. Almost half of the committee joined to improve their CVs and the same number indicated the opportunity to meet other trainees was a reason for joining. Three trainees admitted the opportunity to travel influenced their decision to join.

The committee has commented extensively and made recommendations on various documents produced by the College including the Report of the Special Committee on Psychiatric Training and Practice in British Multi-Ethnic Society and the Working Party report on Good Practice in Discharge and Aftercare Procedures for Patients Discharged from In-patient Treatment.

The current Committee is actively monitoring the escalating costs of the MRCPsych examination and the recently introduced College sponsored Overseas Doctors Training Scheme. The Committee is particularly concerned about the difficulties faced by Irish trainees in obtaining higher specialist training in Ireland. During the term of the present committee working parties have produced reports on the problems of post MRCPsych registrars, management training, reciprocal recognition of post-graduate training, research by trainees and opportunities in Europe.

Working Parties are currently deliberating on psychiatry in general practice and the management of violence.

Women's issues have been accorded a high priority by the present committee and remain a standing item on the agenda. The committee recently organised a trainees' forum as part of the College's Winter Quarterly Meeting entitled 'Getting to the Top? - Women and Careers in Psychiatry'.

Each division organises a yearly Trainees' Day which provides an opportunity for trainees to meet and exchange ideas. The day involves lectures and/ or discussion groups on topical issues relevant to trainees and there is also the opportunity to meet local CTC representatives.

The National Health Service is undergoing significant change. The proposals contained in the White Paper Working for Patients and the impetus towards community care will have far-reaching consequences for trainees in psychiatry. The committee is well placed to represent the interests of trainees and is continually striving to ensure our views are represented and heard in the various decision-making bodies of the College. It is vital that there continues to be effective and vociferous trainee representation in the College. Active and aware trainees are essential for the future of psychiatry; it behoves all of us to accept we have a role to play.

The CTC is open to all inceptors and senior trainees; perhaps you are in a position to contribute to the deliberations of the committee either directly or indirectly. Any trainees who do not know their divisional representatives or wish to find out when the next election will be held should write to the 
secretary of the CTC at the Royal College of Reference
Psychiatrists.

July 1990
Ola Junaid

Honorary Secretary

Collegiate Trainees' Committee
Scort, J. (1986) The functions of the Collegiate Trainees' Committee. Bulletin of the Royal College of Psychiatrists, 10,64 .

\section{Obituary}

\author{
Editor: Henry R. Rollin
}

ThOMAS FORRest MAIN, formerly Medical Director, Cassel Hospital, Surrey

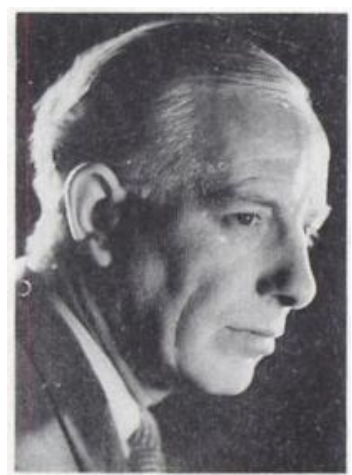

When Dr Thomas Forrest Main, or Tom Main as he was affectionately known the world over, died at his home in London in May 1990, his considerable stature in the fields of psychiatry and psychoanalysis had been well established and had earned him a reputation of the highest order both nationally and internationally. When we remember Tom Main we think of the Cassel Hospital and when we hear of the work of the Cassel Hospital we remember Tom Main. It was there, over a period of some $\mathbf{3 0}$ years, that he applied his considerable intellect, his innate curiosity and perceptiveness, together with his psychoanalytic understanding of individuals, groups and institutions to create and develop a hospital setting which became acknowledged as a model institution and organisation for the care and treatment of the psychiatrically ill person.

Tom Main was born in Northumberland in 1911 and qualified in medicine at Durham University in 1933. He soon entered his chosen field, psychiatry, where his qualities were soon recognised and led to his being appointed as the youngest medical superintendent of his time. In 1940, following the outbreak of war, he joined the RAMC and became Psychiatric Advisor to the 21st Army Group responsible for training army psychiatrists and medical officers in the handling of acute psychiatric casualties and planning for the demands on psychiatric services in the Normandy campaign.
Early in 1945, as the war drew to a close, Lieut Col Main, as he now was, was posted to Northfield, a large military psychiatric hospital just outside Birmingham. His remit was to help the development of group studies in the care and treatment of psychiatrically disturbed servicemen. It was there that he began to formulate and develop his ideas on the institution as a therapeutic environment. This was later referred to as the Second Northfield Experiment and has been written up by Main and others (The First Northfield Experiment was conducted by Wilfred Bion). Main had from his earliest days as a psychiatrist a serious interest in psychoanalysis, and during the war had met and had close working relationships with many psychoanalytic thinkers and practitioners. It followed naturally that, at the end of the war, he began his own psychoanalytic training. He was initially in analysis with Susan Isaacs, then later with Michael Balint, and in addition he had supervision with Anna Freud, Melanie Klein and Paula Heinmann.

In 1946 Main was appointed Medical Director of the Cassel Hospital. It was there that his creative and innovative ideas came to fruition, with the development of his concept of the therapeutic community, his evolutionary ideas on nurse training and practice as a result of which the traditional nursing role changed and grew into a more dynamic psychosocial role. It was in this way that he developed a hospital climate where the doctor could study and take a wider perspective of his role within the total environment.

It was within this developing hospital culture that an extraordinary event occurred which led to quite revolutionary changes in attitudes and practice both within the hospital itself and in psychiatry in general. In 1950 a woman, due to be admitted with a severe psycho-neurotic illness, arrived at the hospital with her very young child and explained that she had 